\title{
OS ANAMBÉ DO ALTO CAIRARI: PAISAGENS DA MEMÓRIA
}

\author{
Eneida Assis ${ }^{1}$ \\ Jorge Lucas Neves ${ }^{2}$
}

Durante o processo de escolha de quais povos seriam estudados no âmbito do projeto Observatório da Educação Escolar Indígena ${ }^{3}$, os critérios adotados para os Anambé foram relacionados ao fato de ser um grupo pouco investigado em período mais recente (Figueiredo \& Vergolino e Silva, 1969; Arnaud \& Galvão, 1969; Julião, 1993) mas, sobretudo, por ter sido estudado por Napoleão Figueiredo e Anaíza Vergolino e Silva, fundadores do Laboratório de Antropologia da Universidade Federal do Pará, local que serviu para a formação dos primeiros antropólogos desta instituição ${ }^{4}$. A oportunidade de conhecer a região do Moju presentemente sob a mira do agronegócio e verificar como estavam os Anambé, um pouco mais presentes para nós através da referencia aos nomes de algumas mulheres pelos trabalhos em linguística de Risoleta Julião, se mostrou oportuno e viável para os objetivos do Observatório. Os Anambé para os postulantes a antropólogos da primeira geração do Laboratório que hoje leva o nome de Napoleão Figueiredo, doravante definido apenas como LAANF ${ }^{5}$, era um grupo indígena que fazia parte da história da antropologia local, porém sem a visibilidade acadêmica de outros povos da Amazônia paraense. Em 1948, Expedito Arnaud foi designado pela $2^{\mathrm{a}}$ Inspetoria Regional do Serviço de Proteção ao Índio/SPI para investigar a situação de um grupo indígena que vivia no rio Cairari, afluente do Moju, conhecidos como Turiwara, e que segundo Arnaud o curto espaço de tempo destinado ao trabalho não permitiu que a identidade do grupo fosse esclarecida. Em 1968, vinte anos depois da primeira visita, este pesquisador acompanhado de Eduardo Galvão ambos do Museu Goeldi tiveram a responsabilidade de avaliar as condições desse povo diante do avanço das frentes de expansão madeireira e exploradores de peles. $\mathrm{Na}$

\footnotetext{
${ }^{1}$ Universidade Federal do Pará, Brasil.

${ }^{2}$ Universidade Federal do Pará, Brasil.

${ }^{3}$ O Projeto Observatório da Educação Escolar Indígena/OEEI é financiado pela CAPES/SECADI/INEP tendo a finalidade de realizar estudos sobre a educação escolar indígena ofertada aos povos indígenas. $\mathrm{O}$ OEEI é um projeto em parceria entre a Universidade Federal do Pará/UFPA, Universidade do Estado do Pará/UEPA e Universidade Federal Rural da Amazônia/UFRA.

${ }^{4}$ Além desses autores, a Enciclopédia Povos Indígenas no Brasil organizado por RICARDO, Carlos Alberto designa um capítulo sobre os Anambé; assim como a dissertação de mestrado em Serviço Social/UFPA de AZEVEDO, Neliza M. T. Reserva Indígena Anambé: Localização e História aborda o papel do assistente social em áreas indígenas.

5 LAANF- Laboratório de Antropologia "Arthur Napoleão Figueiredo".
} 
ocasião o grupo do Cairari era formado por apenas 19 pessoas que se autodenominavam Anambé, identificando outros índios como Turiwara (Arnaud \& Galvão, 1969). Mesmo após o contato do SPI nos anos 1940, a visita de comissões da Fundação Nacional do Índio/FUNAI nos anos 1976 e 1979 e a delimitação da Terra Indígena em 1984, os Anambé não receberam a assistência efetiva dos órgãos indigenistas, fazendo parte dos "grupos esquecidos" como se expressou um técnico indigenista. Mediante o diálogo com os Anambé, com autores que os visitaram em diferentes momentos e personagens não indígenas contemporâneos à visita de Napoleão Figueiredo, a intenção neste artigo é refletir a relação entre memória e esquecimento presentes na história dos Anambé, o caráter polissêmico desses fenômenos, as diferentes paisagens que deles decorrem possibilitando com isso o entendimento da dinâmica da vida social e cultural desse povo.

\section{Buscando os Anambé}

A matéria do Caderno Especial de Aniversário do jornal "O Liberal" de novembro de 1990, denominada "Na Trilha dos Anambé” escrita por Anaíza Vergolino e Silva trata da viagem feita por ela e Napoleão Figueiredo aos Anambé em 1968, na qual participou como aprendiz de antropóloga. A descrição do percurso da viagem a motor saindo de Belém até a localidade de Igarapé-Mirim na região do Tocantins, os diferentes pernoites e paradas para a troca de embarcação, permeadas por informações sobre o movimento de motores conduzindo diversas mercadorias como farinha de mandioca, milho, peles de animais, carne de caça, óleos de copaíba e andiroba, o regatão, o comercio via escambo que retirava a importância do dinheiro em certas negociações, os centros da economia local neste caso as cidades de Igarapé-Mirim, Abaetetuba, Cametá que estabeleciam os preços dos gêneros alimentícios e a margem de lucros da intensa economia dos rios e igarapés, informam ao leitor as paisagens com que se deparam professor e aluna:

Alguns produtos atingem cifras surpreendentes como o café (NCR\$ 2,00), fósforo (NCR\$ 1,00), calça feita (NCR\$ 12,00) [...] Os medicamentos geram um lucro superior a $100 \%$, como no caso do Melhoral em que um comprimido custa NCR\$ 0,20 . [...] Os moradores ficam sempre devendo o regatão. [...] se não saldarem as dividas, perdem o crédito com outros regatões que operam na área, pois eles se comunicam entre si informando o nome do devedor. [...] $\mathrm{O}$ poder político é 'enfeixado' pelo poder econômico: a ação dos comerciantes [...] determinam os 
candidatos no qual os eleitores devem votar. Os eleitos, bem como os chefes políticos, não se interessam pelos moradores da região e não há lembrança de algum eleito ter ido visitar essa região.

Entre aqueles que hospedaram os dois viajantes, há referencia ao Sr. Elias conhecido na região como Santinho Pernambuco, filho de Bernardino Inácio dos Santos, que residiu no Cairari. Foi ele que encontrou os Anambé em um lugar chamado Cipoteua no alto Cairari, por volta de 1928 aproximadamente, e que à época formavam um grupo de 60 pessoas. O Sr Bernardino os convenceu a virem se instalar mais a jusante, próximo ao Lago Grande do Cairari, rico em peixes e terra boa para a agricultura. Em 1944, o Sr Santinho levou ao conhecimento do SPI em Belém a noticia da presença desses índios, mas apenas um funcionário desse órgão, Expedito Arnaud os visitou três vezes levando medicamentos, ferragens e redes. Nesse ínterim do relato, Anaíza faz referencia à imagem que Santinho possuía a respeito dos "doutores da cidade" e o julgamento que fez como sendo pessoas frágeis para a empreitada, sugerindo por isso que alguns índios fossem trazidos para conversar com os "doutores". Porém, diz ela que o que mais o surpreendeu foi "a pouca idade de Anaiza já enfronhada em estudos".

À medida que as ressalvas a respeito deles se diluem, as informações chegam e são introduzidos aos que vivem no Cairari como o pajé Júlio Miranda que lhes falou a respeito dos dois tipos de encantados com nome e sobrenome: os "do mato" como João Curupira e "da água" como Manuel Farias e Maria Farias, um boto fêmea, uma encantada que tem uma cruz no peito. Continuando a subida do Cairari se deparam na região do lago Grande com a aldeia dos Anambé formada por seis casas e localizada em um terreno alto. Foram recebidos pelo cacique Aipã e seu irmão Mukã, suas esposas, filhas que lhes deram as boas vindas, os demais estavam no mato caçando e colhendo frutos. A sobrinha de Aipã, Tapiira será um personagem importante na reconstituição de informações fornecidas a estes autores após 44 anos passados desses acontecimentos. Conforme o relato de Vergolino e Silva a chegada dos "doutores" fez convergir para a aldeia um número grande de pessoas em busca de medicamentos demonstrando aos pesquisadores o esquecimento da região e das pessoas pelos políticos. O relato prossegue sobre aspectos diversos da vida social, econômica e cultural, esta última bastante prejudicada pelo desaparecimento de ritos, da mesma forma que adornos, pinturas ou tatuagens são desconhecidos pelo grupo. No ano seguinte os pesquisadores 
voltaram ao Cairari, mas neste relato não é feita referencia sobre este segundo encontro. A conclusão do relatório é que os Anambé são integrados à sociedade nacional.

Como eram os Anambé? De onde vieram? O Relatório de Domingos Soares Ferreira Penna (1864) informa que eles são oriundos das cabeceiras do Pacajá Grande e que os missionários jesuítas passaram a separar as famílias e levar muitas para Portel, como se não bastasse foram atacados pela tribo Jauorité-tapuira que eram antropófagos os obrigando a se retirar para um dos afluentes do Pacajá, o rio Curuhy onde formaram a aldeia Tauá. Aqui e ali em algum relatório de província aparece uma referencia aos Anambé localizando-os em diversos pontos da região do rio Tocantins (Cunha, 1853; Brusque, 1862).

Ferreira Penna (1864) os descreve como sendo "de cor clara, altos, bem conformados, olhos horizontaes, nariz aquilino; o seo aspecto indicando, como eram todos os indígenas, uma raça que se tornou taciturna e melancólica pelos longos soffrimentos que os colonos europeos lhes infligirão...” (1864: 39). Sobre o caráter desse povo relata um fato que o impressionou muito:

\begin{abstract}
Os homens e suas mulheres são generosos e obsequiadores. Sabendo que costumavão colher castanhas, pedi-lhes que guardassem-nos algumas para a volta. Dous dias se passarão. Cerca de meia hora depois de nosso regresso a aquele pouzo, vimos aproximar-se um deles com sua mulher, curvados ambos sob o peso de um paneiro de castanhas em ouriço, que cada um trazia; uma alça que passava pela fronte dos índios prendia e fazia pender-lhes nas costas os pesados paneiros de castanhas. Elles os depositarão no chão dizendo que erão para nós, e perguntandolhes quanto custava, responderão nesse tom melancólico que lhes é tam comum, menos na significação desta voz: - Não custa nada!” (Ferreira Penna, 1864: 39).
\end{abstract}

O diálogo com os autores que vivenciaram momentos com os Anambé em um passado distante, favorece a incursão em um tipo de memória do grupo da qual pela distancia do tempo dos acontecimentos ocorridos é como "um quadro exterior do qual [se] ignorava a existência" como se expressou Halbwachs (1990: 58). Considerando que, a memória é construída social e individualmente, e também herdada, nela vão se compondo e recompondo as andanças por várias regiões, o desaparecimento físico de muitos em decorrência de doenças como sarampo, maus tratos e fome, ocorrendo uma seleção de temas, alguns pintados com cores mais fortes outras esmaecidas. Alguns membros da sociedade se tornam por esta ou por aquela razão depositários dessas lembranças ao longo das gerações que vão sendo substituídas. O que tem na maioria das vezes ocorrido com os povos indígenas são os efeitos das compulsões sofridas 
provocando a quase extinção do grupo, quebrando o elo entre as gerações de avós, filhos e netos fragilizando as lembranças, dificultando que os mais jovens entrem no mundo dos antigos, a perda da língua, os cantos e danças, o mundo do sagrado que se interrompe, enquanto outras memórias coletivas vão se impondo. Esse estado de acontecimentos está submetido ao desgaste inexorável do tempo. Araújo e Santos (2007), comentando sobre a clivagem entre memória oficial e memórias subterrâneas marcadas pelo silencio apresentadas por Pollak (1989), mostram como essa clivagem pode existir entre a sociedade englobante e grupos minoritários. Na interpretação das autoras "São lembranças "proibidas", "indizíveis" ou "vergonhosas" que muitas vezes se opõem à mais legítima e poderosa das memórias coletivas: a memória nacional" (2007: 104). Quais fatores colaboraram para o silencio que se abateu sobre os Anambé? Será que o fato daqueles que os visitaram no passado remoto e recente, ao observarem que os Anambé por estar a muito tempo envolvidos com a "população civilizada" no dizer de Brusque (1862) se tornavam pouco interessantes para o conhecimento vigente?

\section{Chegando ao Cairari}

A viagem de ônibus de Belém até a cidade de Mocajuba foi tranquila e sem incidentes, na rodoviária local tomamos um taxi até a margem do rio Tocantins onde seguimos em outro ônibus até a Vila Elim. Nosso contato, uma assessora da Prefeitura de Moju que reside no local, já havia falado com o cacique Cafu, a respeito de nossa visita. O ônibus seguiu por uma estrada de chão cheio de curvas e entradas deixando passageiros e mercadorias em lugares que pareciam ter apenas uma ou duas casas. Os passageiros transportavam todo tipo de mercadoria: sacos de cereais, material de construção, móveis, gaiolas com animais, enquanto alguns aproveitavam para vender lanches durante o trajeto. 

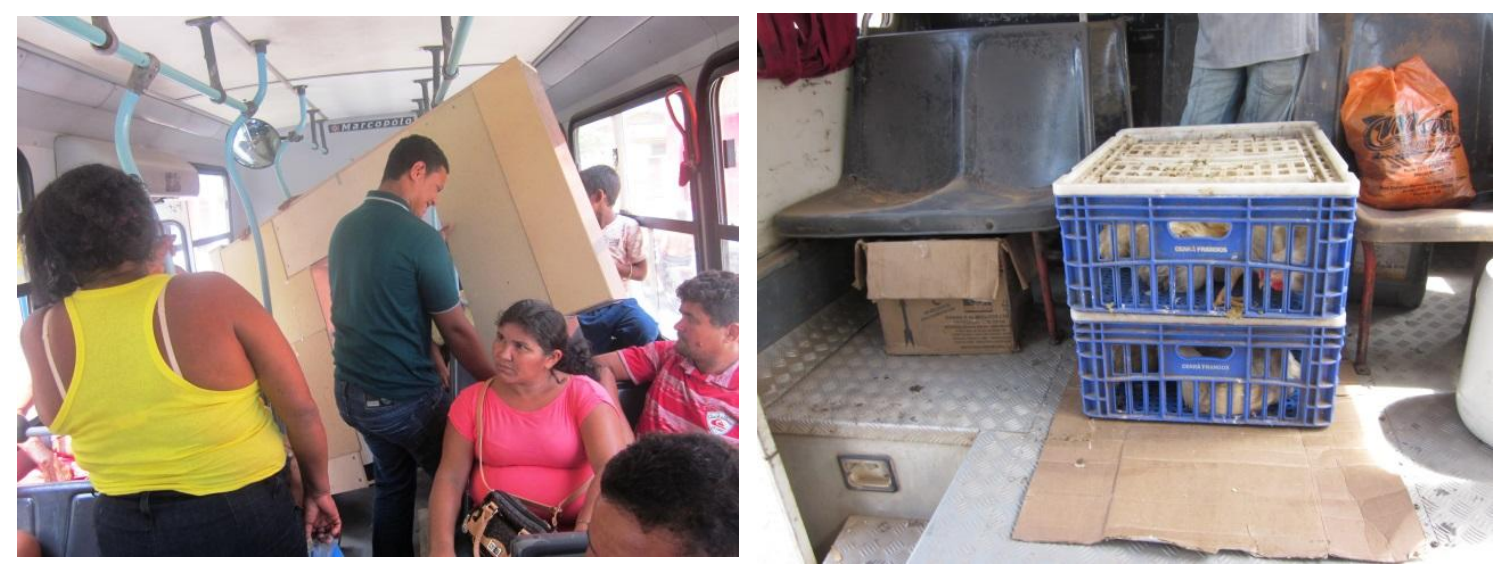

Foto 1 - Interior do ônibus que se viaja até a Vila Elim

Chegamos ao anoitecer à casa de nossa anfitriã à margem da confluência dos rios Apeí e Cairari e na manhã seguinte seguimos em direção à aldeia dos Anambé. O Cairari é um rio de águas claras ainda piscoso e pequenas praias que se distribuem aqui e acolá, margeado por mata ciliar na qual se vê árvores frondosas e alguns locais de mata alagada. Na direção à montante encontra-se o lago Grande com trechos assoreados que formam ilhas submersas e por ser época de eleições encontramos cartazes de candidatos fincados nos bancos de areia compondo um elemento extra à paisagem, a apropriação de um caminho fluvial percorrido por moradores diariamente.

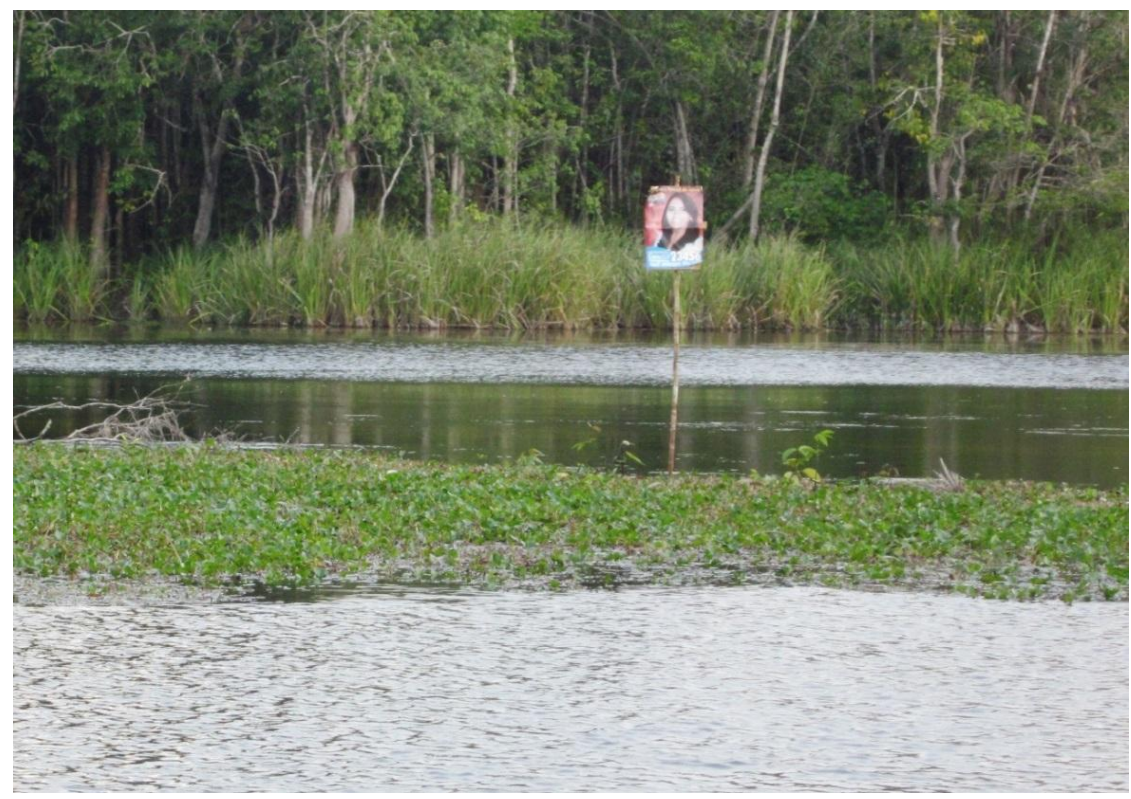

Foto 2 - Propaganda eleitoral no Rio Cairari 
Após uma curva do rio se depara com o porto da aldeia cercada por vegetação abundante, na parte alta do terreno se localiza a aldeia com casas que se distribuem à primeira vista em torno de espaços onde ficam a escola e o posto médico. Um grupo de pessoas estava reunido ralando mandioca para o preparo da farinha, e por estarem cientes de nossa chegada entendemos que as apresentações e objetivos de nossa visita deveriam acontecer ali mesmo. A referência ao "Doutor Napoleão" funcionou como senha de aceitação e de acesso ao passado que desejávamos conhecer, mas, especialmente o que veio depois, mesmo sabendo que não seria possível em um primeiro encontro. Em todo caso, aquela cena foi a primeira impressão que tivemos dos Anambé, homens, mulheres e crianças sentados em circulo em pedaços de troncos em silencio enquanto descascavam mandioca, outros atendendo alguma criança em voz baixa, a atenção voltada para o que estávamos apresentando e a gravação dos relatos dos mais velhos. Pouco a pouco uma pessoa ou outra se apresentava podendo ser um conselheiro, um morador de algum ponto da reserva que vinha explicar de que forma os Anambé estão organizados ou uma mulher que se oferecia para preparar uma merenda, e descobríamos que não apreciavam enlatados, apenas comida fresca.

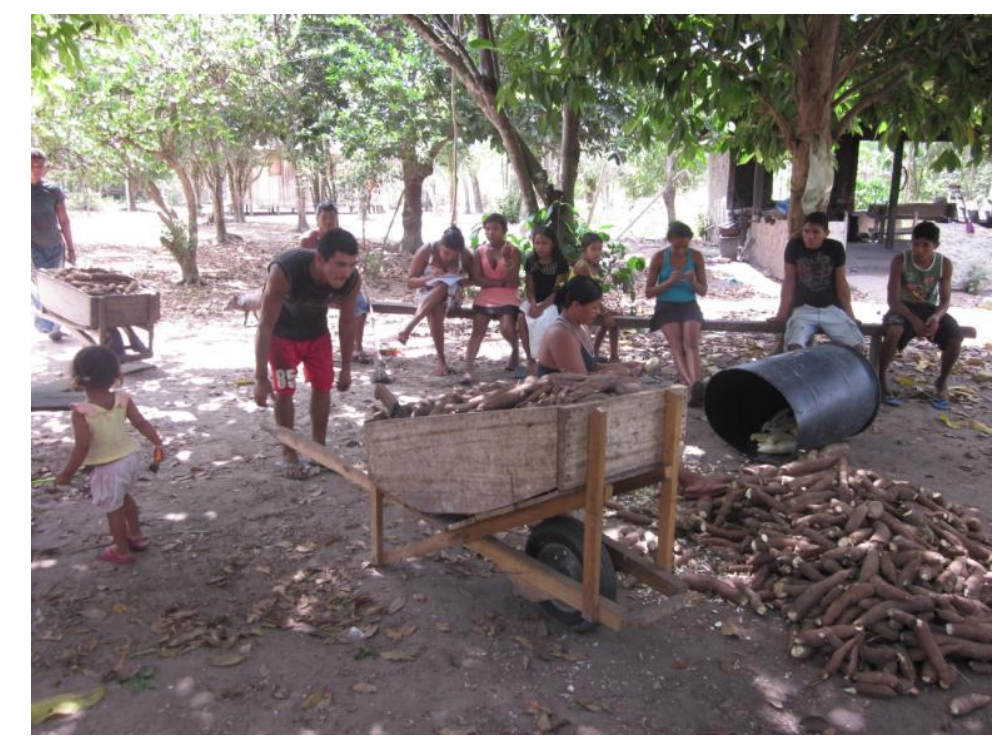

Foto 3 - Pessoas descascando mandioca 


\section{Encontrando Tapiira}

As mulheres parecem ter o papel de guardiãs da memória coletiva do grupo. Sobre o passado, as figuras de Tapiira mãe de Raimundo, o Cafu, um dos caciques, Titon, prima de Tapiira, são as que conservam a maior parte da memória pregressa do grupo, além de serem elas que têm conhecimento da língua anambé. Outra mulher de nome Arara, cujo nome brasileiro é Severina, é falante da língua, mas, em virtude de problemas de audição tem maior dificuldade em prestar informações. No momento presente, Vanusa, mulher de Cafu, tem um papel político e social importante, faz parte do Conselho da aldeia sendo responsável pelas questões da educação, que a leva a participar de reuniões dos Anambé com a sociedade de fora. Além disso, por ser artesã está sempre cercada por crianças que vão aprendendo a conhecer sementes, fibras e outros materiais para confecção de colares, braceletes e cestaria que deve ser confeccionado segundo ela "sem miçangas, pois não são coisas de índios".

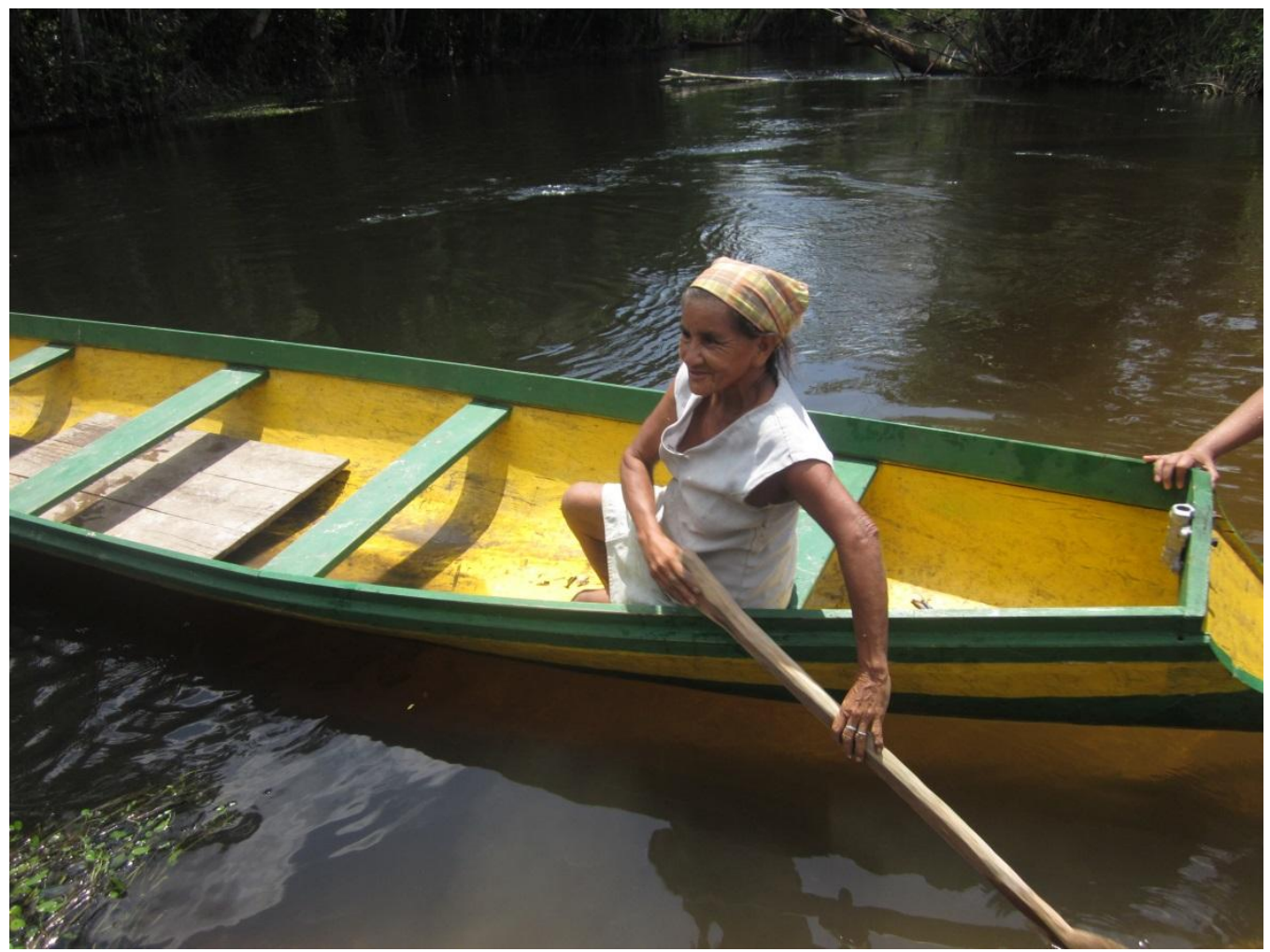

Foto 4 - Tapiira Anambé

Nos relatos sobre a vinda para a região do Cairari, as lembranças foram sendo fornecidas pelas mulheres mais velhas e também por Cafu que as auxiliava na 
reconstrução do trajeto histórico segundo a memória do grupo. Nesse esforço da memória aparece a figura de Quatimá ou Maria de Belém que relatou para eles há muito tempo atrás, o trajeto dos Anambé até chegarem ao Cairari:

\begin{abstract}
Ela contou sempre um pouquinho da historia, da onde vieram, eles vieram do Acara, do Acara eles vieram para o rio Capim. No rio Capim tiveram uma, como é que se diz? uma briga entre índio mesmo, com os Gavião, certo? Ai de lá aconteceu uma separação deles, [dos Anambé] tiveram uma briga muito grande com eles lá [Gavião] ai, sei que, de lá eles vieram para cá no rumo do Cairari, que era... como é que dá o nome? (Cafu).
\end{abstract}

Tapiira completa o trajeto dos Anambé após o encontro com os Gavião:

Eles vieram primeiro pro Cipoteua, do Cipoteua eles vieram pro Marinheiro. De lá eles vieram pra ai [em direção à jusante do rio], então quem trouxe eles pra cá, foi um tal de Antônio dos Santos parece que foi ele que trouxe eles pra ai. Antônio dos Santos era um senhor que morava aí em baixo, só que ele já morreu também. Ele andava caçando, ai pra cima, mariscando, né? Foi ele que localizou eles ai no meio da mata ai foi ele quem amansou os índio mais velho, ne? Ai é que trouxeram eles pra cá até onde eles chegaram nessa outra aldeia, era Procópio, a outra aldeia. [...]Mas, tem outras aldeias, o Marinheiro é um lugar, meu cunhado mora lá, Cipoteua é uma fazenda, tem o Urubu, o Bacuri acima do Procópio lá a gente se criou. Quando o Napoleão veio nós morava no Procópio, lá onde o Napoleão vem com nós, foi lá que ele teve com nós.

No relato de Julião (1993: 18) esta autora considera que até onde a memória do grupo alcança, os primeiros Anambé vieram das bandas do Moju e se instalaram no Igarapé Cipoteua, seguida do Marinheiro e, posteriormente, "mais abaixo, entre o igarapé Bacuri e o Furo do Bacurí, sempre na margem esquerda". É desse ponto que seguindo a jusante se transferiram para a margem direita onde está localizada a antiga casa do Posto da FUNAI. Segundo Julião, até essa transferência ainda mantinham o sistema de uma única aldeia. Após a demarcação, para efeito de ocupação da reserva, algumas famílias passaram a viver em diferentes pontos da reserva, "sempre ao longo do rio, não havendo moradores na área de campo que fica na parte de trás da reserva, aonde só vão para apanhar bacaba, cortar cipó, ou para eventual verificação dos limites".

Os Anambé desde os anos 1970 não recebiam assistência efetiva do órgão indigenista, até que em 1984, solicitaram providências quanto a regularização de suas terras em vista da presença de madeireiros. Desde 1976, o órgão indigenista tinha conhecimento dessa situação através de um relatório relativo à proposta de demarcação da terra, retirada de madeireiros e segundo Ricardo (1985) esta proposta foi arquivada. 
Em 1982, um grupo chefiado por Aipã acompanhados do Sr. João Simão foram a Belém solicitar apoio, em troca o Delegado da $2^{\mathrm{a}}$ DR (Delegacia Regional da FUNAI) sugeriu a transferência dos mesmos para o Guamá onde viviam os Tembé. Um total de doze famílias se instalaram no Guamá na região do igarapé Tawari, entre os rios Guamá e Piriá, as condições eram difíceis e, apesar da retirada de colonos havia instabilidade na região levando os Anambé a retornarem ao Cairari. Enquanto estas famílias estiveram fora ocorreram invasões na área pretendida por eles, lhes dando maior convicção sobre a necessidade de demarcar sua terra, o que ocorreu em 1984 (Affonso, 1984e). Estes eventos são lembrados por Cafu e Tapiira cujas lembranças permitem que se perceba a importância da demarcação da terra para os Anambé:

$\mathrm{Na}$ verdade, nós, antes de demarcarem essa área aqui, né? Ninguém não teve problema nenhum não, houve uma época em que fomos transferidos lá pra Capitão Poço, lá com os Tembé, mas foi o pessoal ai, por aqui ficou só eu, o Cameni, ela aqui [Tapira] e o... Arara, ai que o resto eles foro pra lá. (Cafu).

Em prosseguimento ao relato, Tapiira considera que:

Quem foi pra lá foi o finado Aipã, Camapú e o meu filho, Murru. A filha do Mambo também estava pra lá. Quem transferiu foi o pessoal da FUNAI. Ah! o Macaco, estava pra lá também, agora ele mora, ai no Mocajuba. Depois todo mundo voltou quando mataram um pra lá, ai vieram embora. Ai ele (Macaco) foi morar ai no Mocajuba. Ele morava pra cá primeiro, pro centro, tinha uma casa dele lá pro fim da reserva, pra Camaiateua.

\section{Mulheres e seus testemunhos}

Os testemunhos segundo Halbwachs (1990) servem para fortalecer, debilitar ou completar o que se sabe de um evento, neste sentido as testemunhas são importantes que nos relatam o que ouviram das lembranças de outros e deles mesmos, portanto, nossas memórias são coletivas. Pollak (1989) chama atenção sobre o papel da memória subterrânea que resulta da intervenção dos atores no trabalho de reconstituição e de formalização das memórias, o que se observa nos relatos nos quais alguns personagens ou acontecimentos como os de caráter particular funcionam como sinalizadores do tempo passado que se quer lembrar.

A lembrança pelas mulheres Anambé dos acontecimentos passados parece estar ligada ao papel que elas ocupam no grupo social, em função da idade, do lugar na rede de parentesco, mas, sobretudo por serem elas, que têm mantido a língua e as tradições como informa Julião (1993:14): 
Serviram, sistematicamente, como informantes duas índias - Tapiira e Durica - mãe e filha, respectivamente. Entre os homens apenas um deles - Paremu, mais conhecido como Alfredo, deu algumas informações. [...] percebe-se nele o gradual esquecimento daquela que provavelmente seja sua língua materna, em virtude de sua substituição pelo português. Contou-se, ainda, sobretudo na confirmação de dados, com a ajuda esporádica de Maria de Belém, uma das índias mais velhas, por meio de quem se conseguiu um canto de cura. [...] foram de grande ajuda as interferências de Maria Olinda, 28 anos, (considerada aqui bilíngue passiva), filha de mãe índia, que indicava a tradução correta, além de ajudar na transcrição das fitas.

O fato de serem "integrados à sociedade nacional", conforme a literatura existente pode dar a ideia de que nada mais existe da cultura deste povo. O texto de Julião fornece pistas sobre a manutenção de aspectos do modus vivendi Anambé no qual se destaca o papel da mulher na produção de utensílios e equipamentos importantes para o cotidiano da vida social e cultural:

[...] As redes, há muito deixaram de confeccioná-las, preferindo adquiri-las no comércio, havendo uma das mulheres - Durica - que ainda sabe fiar, tendo confeccionado algumas redes nos últimos dois anos com algodão de calafetar barco. Antes da introdução do algodão, as redes eram confeccionadas com envira, assim como as saias que as mulheres usavam, segundo relato de Durica. (Julião: 23)

Os instrumentos de caça e pesca, utensílios de madeira e paneiros de carga pertencem ao universo masculino, porém a escassez de matéria prima ameaça essa tradição:

[...] pilões, arcos, flechas, zagaias. [...] As duas últimas oferecem certa dificuldade na confecção, em virtude da escassez da taquara e aquelas feitas de varas não favorecem o manuseio. As pontas das flechas são de madeira e as das zagaias são de prego limados de forma a adquirirem dois pares de dentes cada. Os cestos de carga ainda são usados, havendo alguns homens que sabem tecê-los. (Julião: 23).

No momento presente, Vanusa, que é membro do conselho, diz que um dos problemas sérios à continuidade do que ela considera "as coisas de índio" é o desaparecimento gradativo de certas espécies vegetais como cipós, sementes, envira, frutos dos quais se tira o sumo para pintura, e que estão esparsas pela área. A dificuldade em encontrar os materiais necessários à confecção do artesanato os leva a um gasto de tempo maior, mesmo assim, é necessário incentivar o artesanato e “inventar”. Nas imagens abaixo, vê-se Vanusa utilizando um pincel atômico para fazer as pinturas com tinta de jenipapo, e o professor aplicando a técnica em um de seus alunos. 


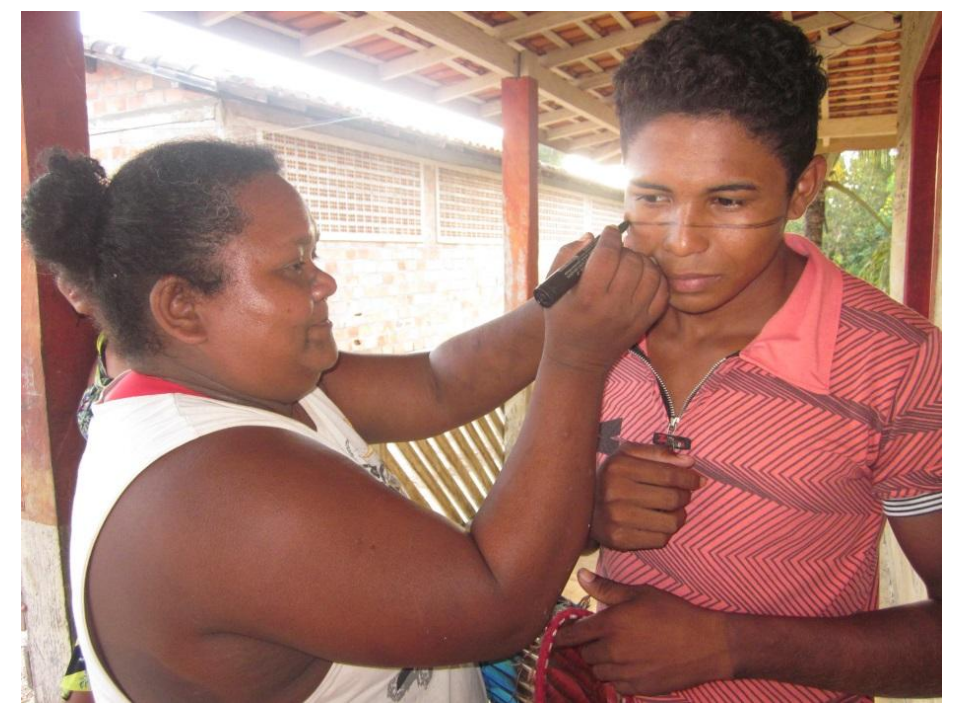

Foto 5 - Vanusa e as novas formas de pintura

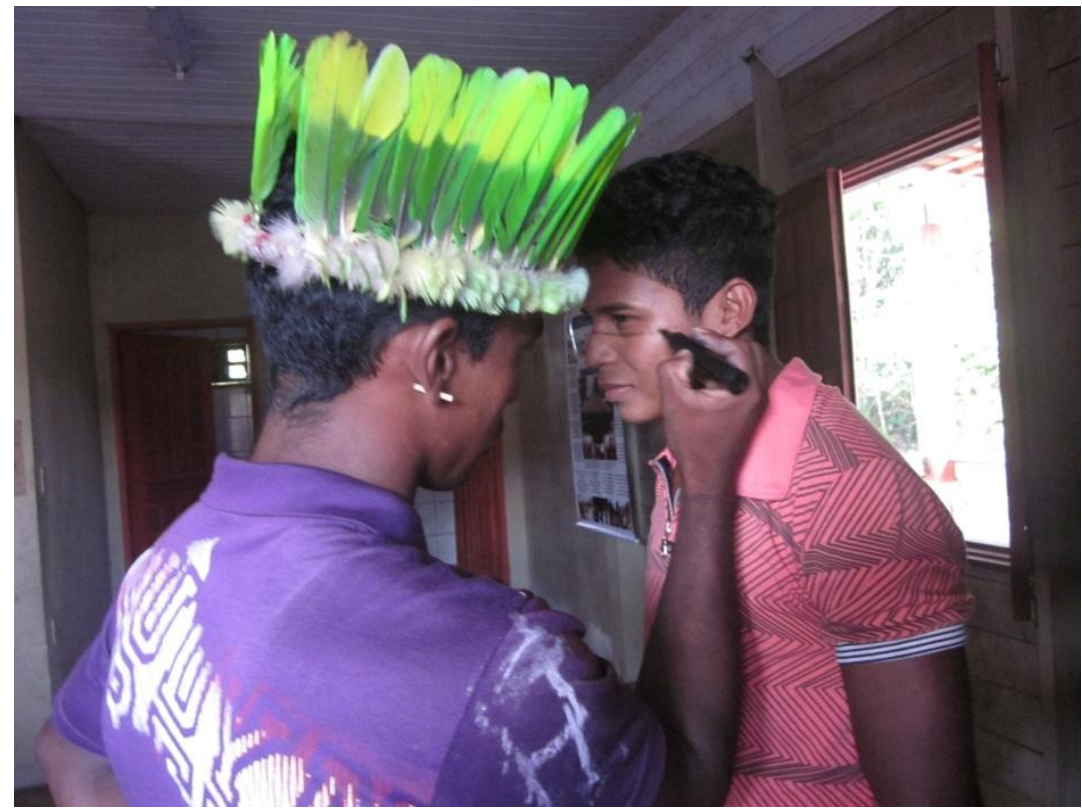

Foto 6 - Professor utilizando a técnica de Vanusa

A pressão exercida por madeireiros, caçadores de peles, coletores de resinas e óleos ao longo do tempo, tem reflexos na diminuição da fauna e flora que afeta a segurança alimentar do grupo, conforme as falas de Tapiira e Titon, a Juruti.

Tinha muita caça, o peixe ai no lago tinha muito e [se] matava com a porunga, porunga é uma lamparina, uma lata. Com a porunga se matava ai no lago, alumiava e cortava com terçado. Não tinha zagaia [de] primeiro. Agora tem zagaia pra matar peixe. Tinha muito peixe. Era só tuum, pronto! (Tapiira). 
Em seu relato enfatiza a fartura de peixe que existia no lago Grande:

Era só na cortada, lá na frente cortava, lá na frente cortava de novo. Tinha era muito peixe, nesse lago ai. Mas agora... não tem mais, tá arisco o peixe.

Titon complementa informando sobre a caça:

Tinha muito pra ali, tapii, tatu, teitetu... é catitu. É, tinha muita caça, mas agora. Os pássaros? O que se comia? Jacu, juruti, mutum, jacami. Tinha era muito, mas agora... Primeiro tinha era muito. Cada pássaro por ai também, ai na vila, vindo lá da vila tinha também muito catitu ai no campo. Tinha muita caça pela beirada ai também. A gente matava, a gente vinha cheio de caça pra levar lá pra vila. Mas agora... não mata mais. Tá muito arisco. Tinha era muito. Muita caça e peixe também.

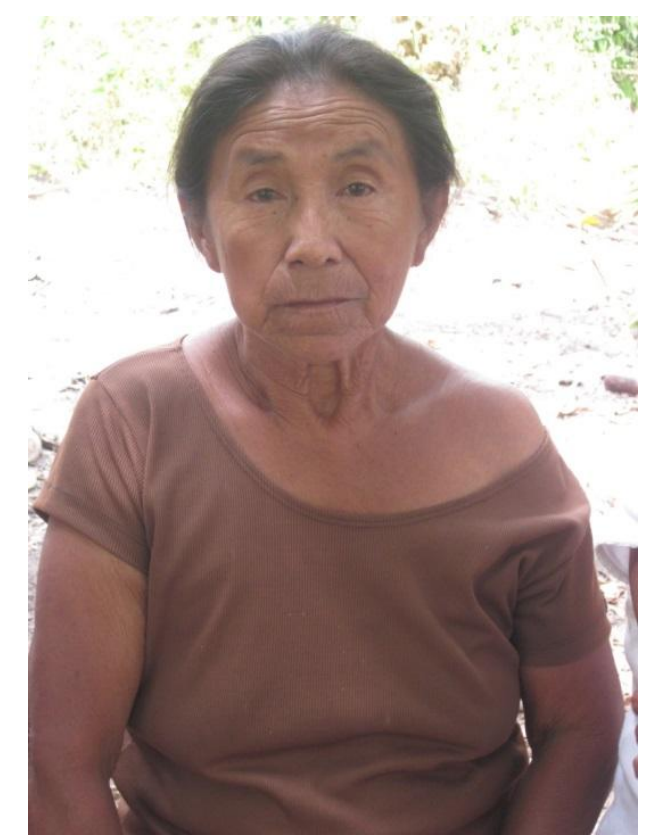

Foto 7 - Titon Anambé

Os relatos fornecem um quadro das paisagens do Cairari no qual, a fartura de peixe e caça permitia um excedente para a venda, o que não é mais possível no momento presente, mas também a manutenção de uma maneira de viver e agir, e que está mudando. Silveira (2009: 72) alerta que as paisagens são cenários ativos, que têm relação com os diferentes aspectos socioambientais decorrentes das ações humanas que estão, em seus termos, "em profunda interação com o entorno, definindo, assim, formas de relação mais ou menos transformadoras do meio". Para o autor, ocorre uma 
apropriação criativa do real pelos sujeitos em interação com os ambientes, resultando em impactos que variam de acordo com os caminhos percorridos pelos sujeitos da ação.

As pressões sobre a terra dos Anambé repercutiram no abastecimento. Julião registra que moradores da região costumavam entrar na parte de trás da reserva para caçar e o rio e o lago sofriam a "concorrência desleal dos madeireiros que usam os faróis dos barcos para a pesca noturna" (1993: 27). Ao lado disso, a ação sistemática da pesca predatória, o uso de batimento de ervas como timbó, ocasionaram confrontos com moradores de outras localidades. A expressão "vamos passar fome de farinha" mesmo havendo outro tipo de alimento, observada por Julião, é algo que retorna hoje em vista do avanço das plantações de dendê para a indústria do óleo de palma. No entorno da Terra Indígena (TI), pequenos agricultores venderam suas propriedades repercutindo sobre o destino de algumas comunidades que estão ameaçadas de desaparecer pela migração de muitas famílias para as cidades próximas, de acordo com as informações recebidas no local da pesquisa. O efeito que esse modelo econômico possa ter sobre os Anambé ainda não está sendo discutido entre eles, o que sabem é que é algo novo e poderoso, algo que pode encurrala-los e oferecer perigo à vida como conhecem. Sobre a ação da produção do óleo de palma na microrregião de Tomé Açu onde se situa o Município de Moju, Backhouse (2013) registra que em outros municípios pertencentes à microrregião ocorre a compra de pequenas propriedades que terminam abalando povoados inteiros, um anúncio de que no futuro a agricultura familiar que se caracteriza pela produção de alimentos seja substituída pela cultura da palma. Que cenário se vislumbra para os Anambé em uma correlação de forças quando existe como afirma Backhouse (2013: 22) uma "crassa assimetria de poder dentro da microrregião, assim como a marginalização da população local é não apenas aproveitada, senão reproduzida, quando tematizada em contextos transnacionais"?

\section{Memória e esquecimento, faces da mesma moeda}

A memória em seu processo de recuperação das coisas passadas seleciona o que "pode ser" expresso e guarda ou elimina temporariamente o que não deve ser dito, temas, questões ou situações que entram no campo do esquecimento. Evidentemente que, se há usos da memória, há também, usos do esquecimento. Segundo Yerushalmi (1989: 19), esta atitude pode apontar para o uso que se pretende dar ao esquecimento. 
Padrós (2013) considera que refletir sobre a memória implica em reconhecer que há, como contrapartida, o esquecimento, os silêncios e os não-ditos. Nesse sentido, diz ele, o esquecimento pode se apresentar como uma opção de restrição ao que é essencial a certos fatos ou informações a respeito deles. Mas também pode ser o resultado de uma ação deliberada de ocultamento. Existe de fato um "esquecimento institucional" ou os Anambé a semelhança de outros povos iniciou um processo de organização mais aos moldes do movimento indígena, ao mesmo tempo em que providenciaram suas articulações locais se colocando como um novo ator social e político na região do Cairari?

Os Anambé tem hoje uma população de 144 pessoas distribuídas em 50 famílias. A presença feminina é predominante com 76 mulheres e 68 homens. A população jovem perfaz um total de 110 pessoas com idades que variam entre 14 a 30 anos; desse total, 90 estão em torno dos 20 anos, enquanto a população acima de 65 anos se reduz a 9 pessoas. Sobreviver, administrando as perdas, parece ter sido uma constante na história do grupo. A população Anambé passou, no período compreendido entre os anos de 1940 e 1984, por instabilidades no que tange à sua densidade demográfica. Foram momentos que alternaram entre crescimento e decréscimo populacional. A tabela abaixo, elaborada por Ricardo (1985), mostra esse processo:

\begin{tabular}{lcl}
\hline Ano & População & \multicolumn{1}{c}{ Fonte } \\
\hline $\mathbf{1 9 4 0}$ & 60 & Figueiredo (1983) \\
$\mathbf{1 9 4 1}$ & 32 & SPI (1941) \\
$\mathbf{1 9 4 8}$ & 32 & Arnaud \& Galvão (1969) \\
$\mathbf{1 9 6 8}$ & 19 & Arnaud \& Galvão (1969) \\
$\mathbf{1 9 6 9}$ & 22 & Figueiredo (1983) \\
$\mathbf{1 9 7 3}$ & 29 & Silva (1973) \\
$\mathbf{1 9 7 9}$ & 48 & $2^{\circ}$ DR/FUNAI (1979) \\
$\mathbf{1 9 8 3}$ & 61 & CIMI NORTE II (1983) \\
$\mathbf{1 9 8 4}$ & $32($ na AI) + & \\
& 23 (fora da AI) & $2^{\circ}$ DR/FUNAI, Affonso (1984) \\
\hline
\end{tabular}

Tabela 1 - Evolução da população Anambé no Rio Cairari de 1940 a 1984

A partir de 1988 com a assistência efetiva da Fundação Nacional do Índio/FUNAI e a instalação de um Posto na aldeia, a escola foi instalada funcionando de forma ininterrupta até o ano de 1992. Atualmente, há uma escola administrada pela Secretaria de Educação do Município de Moju que funciona como anexo de uma escola do mesmo 
município, um posto de saúde da SESAI - Secretaria de Saúde Indígena. Após a demarcação da Terra Indígena Anambé, houve a distribuição de famílias em diferentes locais do território, e que eles chamam de "núcleos", uma reinterpretação da antiga forma de organização em grupos familiares. As decisões de caráter interno e externo são tomadas através de dois caciques e um conselho. Mediante relações de amizade com o pastor da Igreja Evangélica da Vila Elim, a MEIB-Missão Evangélica Índios do Brasil, Secretaria de Educação do Moju, os Anambé tecem suas parcerias que os auxiliam nas articulações com a sociedade mais ampla e no atendimento de suas demandas e saem do âmbito local para o global.

\section{Referências}

AFFONSO, Carmem. Informação sobre os Anambé. Belém, nov. 1984e. 6 p., dat.

ARAUJO, Maria Paula Nascimento; SANTOS, Myrian Sepúlveda dos. História, memória e esquecimento: Implicações políticas. Revista Crítica de Ciências Sociais [Online], 79 | 2007. URL : http://rccs.revues.org/728 acesso em 30.09.2013.

ARNAUD, Expedito; GALVÃO, Eduardo. Notícia sobre os índios Anambé (Rio Cairari, Pará). Boletim do Museu Paraense Emílio Goeldi. N.S. Antropologia. Belém (42), setembro, 5, 1969.

AZEVEDO, Neliza Maria Trindade. Reserva Indígena Anambé: Localização e História. In: Crianças e Adolescentes Anambé - Cultura e Perspectivas: Subsídios para a intervenção do Serviço Social em área indígena. 2005.95p. Dissertação de Mestrado em Serviço Social Centro Socioeconômico da Universidade Federal do Pará.

BACKHOUSE, Maria (2013): A desapropriação sustentável da Amazônia. O caso de investimentos em dendê no Pará, Fair Fuels? Working Paper 6, BElim. http://www.fair.fuels.de/data/user/Download/ver acesso em 02/10/2013.

BRUSQUE, Francisco Carlos de. Relatório apresentado à Assembleia Legislativa da Província do Pará na primeira sessão da XIII legislatura em $1^{\circ}$ de setembro de 1862. Pará, 91.p., anexos, 1862.

CUNHA, José Joaquim da. Falla dirigida à Assembleia Legislativa Provincial, na abertura do dia 15 de agosto de 1853. Pará, 40 p., anexos, 1853.

FERREIRA PENNA, Domingos Soares. Relatório do Secretário da Província Domingos Soares Ferreira Penna. O Tocantins e o Anapu. Pará, 1864.

FIGUEIREDO, Napoleão; SILVA, Anaíza Vergolino e. Projeto Cairari: Diário de Campo. Belém. Universidade Federal do Pará. 1969. 
GOMES, Jussara Vieira. Grupos Indígenas Amanayé e Anambé do Pará (Relatório). Boletim do Museu do Índio. Documentação, no 7, Dezembro, 1997.

HALBWACHS, Maurice. A memória coletiva. São Paulo. Vértice Editora, 1990.

JULIÃO, Maria Risolêta Silva. A Língua dos índios do rio Cairari. 1993. 139 f . Dissertação (Mestrado) - Curso de Mestrado em Letras, Centro de Letras e Artes, Universidade Federal do Pará, Belém.

NEVES, J. L. G. S. Etnografia da Educação Escolar Indígena ofertada aos Anambé do MojuPará (Relatório de Iniciação Científica/ CAPES). Belém; 2012. 21p.

PADRÓS, Enrique Serra. Usos da memória e do esquecimento na História. In Revista Literatura e autoritarismo. O esquecimento da violência. $N^{o}$ 4. Santa Maria, RS: Universidade Federal de Santa Maria, 2013. http//w3.usfm.br/grpesgla/revista/num4/index acesso em 9/10/2013.

POLLAK, Michael. Memória, Esquecimento, Silêncio. Estudos Históricos. Rio de janeiro, vo.l 2, n. 5. 1989, p. 3-15.

RICARDO, Carlos Alberto (Coord.). Povos Indígenas no Brasil. São Paulo: CEDI, vol 8, 1985.

SILVA, Anaíza Vergolino e. Na trilha dos Anambé. O Liberal, Belém, 15 de nov. 1990. Caderno Especial de Aniversário, p. 7-11.

SILVEIRA, Flávio Leonel Abreu da. A paisagem como fenômeno complexo, reflexões sobre um tema interdisciplinar. In. SILVEIRA, F. L. A. da; CANCELA, C. D. (Orgs.). Paisagem e cultura: dinâmica do patrimônio e da memória na atualidade. Belém: EDUFPA, 2009.

YERUSHALMI, Yosef H. et al. Usos del Olvido. Buenos Aires: Nueva Visión, 1989.

Recebido em: 15/09/2013

Aprovado em: 10/10/2013 